DERMATOLOGY.

UNDER THE CRARGE OF

LOUIS A. DUHRING, M.D.,

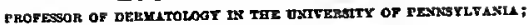

AND

MILTON B. HARTZELL, M.D.,

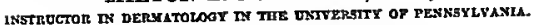

\title{
Papenent-celled Eprthelioma.
}

IN a histological study of epithelioma (Annales de Derm. et de Syph., 1894, No. 2) Keser arrives at the followiag conclusion: The figures ohserved in opithelioma, and described as heiag coccidis, undouhtedly exist, hut they are nothiag else than the result of a ty pical degeaeration of the epithelial cells. The nuthor's reasons for this conclusion are:

1. Neither spores nor sporiferous cysts nre found in epithelioma, nor any other species of figures comparable to any parasite.

2. All the stages of regressive erolution of the cell have heen observed from its heginning, when the nucleus of the iacluded fgure is still completely ideatical with that of the enveloping cell, or of the neighhoriag cells, up to the period whea the nnalogy with $\mathrm{n}$ coccidium hecomes most striking.

3. The manner in which the degenerated protoplasm behares in the presence of certain coloring matters, either in the beginning or at the ead of its metamorphoses.

4. Identically the same figures are fon nd in $n$ physiological tissue where all intervention of a parasitic nature can he excluded, viz., in the halanopreputial groove of the fotus.

\section{Lupus Erythematosgs as ay Imitator of Vamious forars of Dersratitis.}

Radelif Crocker (Journ. Cut. and Gen.-Urin.Dis., Jnnuary, 1894) takes the view that lupus erythematosus comes hut little, if at all, hehind eczema, scahies, and syphilitic eruptions in polymorphism, and gives enses in which it simulated erythema tuherculatum, erythema diffusum, psoriasis guttata, lichen planus in patches, lupus vulgaris in multiple single nodules, or small groups of nodules, and patches of telagiectrsis.

\section{Invasion of the Body by Cocci from the Shin in Eczeara.}

Berwherar (Centralbl.fur Baleriologie, Feh. 5, 1894) gives the notes of a case of very exteasive eczema in aa infant aged four months which terminated fatally. The autopsy revealed acute enteritis, swelling of the spleen, parenchymatous changes in the liver, and ademn of the lungs. The author supposes that the cocci preseat in the various parts had entered hy the skin, aad that the fatal resalt was dne to septic intoxication hy the products of the 
microhes, which had entered from the surface. At the point of entry the epithelium was lacking, and the cocci conld be traced through the corium to the snhcutaneous tissae and lymphatic spaces, in which they were fond ahundantly. A sudden fatal termination in suckling infants affected with eczemn has also heen ohserved hy $O$. Wyss.

\section{madera Diseage (MYcetoma) and Activouycosig.}

A. A. KAxthack (Journal of Pathology and Bacteriology, 1893) bas demonstrated the-correctness of the views expressed hy Vandyke Cartar, who first recognized Madura foot as a distinct disease, and stated that it was probahly due to the asme fungus as actinomycosis. KANTHACK examined fifteell specimens of the disease-twelre of the "ochroid" and three of the "melanoid" variety. He concludes that the fish-roe-lika granules of the yellow variety were undoubtedly a form of rara fungus, and tha hinck masses in their most perfect form a lika parasite in a state of degeneration. The a ame "dospora indica" is suggested for the parasite, with, for the preseat, two varieties-" flara" and "nigra."

\section{The Brovogy of the Ringworm Oaganisy.}

MAGFAYDEN (Brilish Sfedical Journal, September 22, (894), endeavoring to determine whether the trichophytoa produces ferments, summarizes the results of his research as follows:

1. "The ringworm orgaaism produces a proteolytic eazyme which liquefies gelatine verg rapidly.

2. "This enzyme is capable of acting even when diluted, and is very stahle, as its action cas be demosstrated ia cultures three moaths old.

3. "This enzyme acts most rapidly st or pear hlood-heat. At hlood-heat a complete liquefaction of 10 per cent. gelntine was produced in fifteea to seventeen bours.

4. "Exposure to a temperature of $100^{\circ} \mathrm{C}$. for two minutes destroys the ferment.

5. "The proteolytic eazyme is also produced in simple bcef broth; acidity hinders and alkalinity favors its production.

6. "The gelatine containing the active enzyma did not exert nny inimical action upon the staphylococcus pyogenes aureus or the hacillus pyocynneus.

7. "The formation of a diastasic ferment by tha ringworm organism was not demonstrated, hut it grew well in solntions of grupe-sugar and milksugnr.

8. "A slight growth was ohtained on cane-sugur soils and evidence ohtained of the presence of $\mathbf{n}$ feehle inverting ferment.

9. "A milk-curdling ferment is not prodnced hy the trichophyton.

10. "The hest soil for its growth was Dr. Snhouraud's heerwort agar, consisting of heerwort with the nddition of 1.5 per cent. of agar.

11. "It may he that tha proteolytic enzyme aids the organism in softening the tissues and overcoming their resistance to the penetration of the hyphre. It wonld he interesting in this connection to test the action of the enzyme on keratin, and experiments are heing at the present time carried out in this direction." 